Флиер Андрей Яковлевич — доктор философских наук, профессор, главный научный сотрудник Российского научно-исследовательского института культурного и природного наследия им. А. С. Аихачева. Адрес: 129366, Россия, г. Москва, ул. Космонавтов, А. 2. Тел.: +7 (495) 686-13-19. Эл. aspec: andrey.flier@yandex.ru

Flier Andrey Yakovlevich, Doctor of Philosophy, Professor, Principal Research Fellow, Likhachev Russian Research Institute for Cultural and Natural Heritage. Postal address: 2, Kosmonavtov St., Moscow, Russian Federation, 129366.Tel.: +7 (495) 686-13-19. E-mail: andrey.flier@yandex.ru

DOI: $10.17805 /$ zpu.2020.1.9

\title{
Стратегии взаимодействия с чужим в мировой культуре
}

\author{
М. А. ПОЛЕТАЕВА \\ МОСКОВСКИЙ ГОСУДАРСТВЕННЫЙ ЛИНГВИСТИЧЕСКИЙ УНИВЕРСИТЕТ
}

Статья посвящена рассмотрению трех основных стратегий отношения к чужому, имевших место в истории: изоляционизм, ассимиляция и мультикультурализм. Они в основном базировались на общих характеристиках мировоззрения той или иной эпохи.

В доиндустриальную эпоху отношение к чужому в основном строилось на стратегии изоляционизма. Чужие (инородцы, иноверцы) поселялись отдельно, в особых кварталах, и их контакты с местным населением были строго ограничены. Это строилось на представлении о том, что чужие созданы не по образу и подобию Божьему, а являются порождением дьявола и несут угрозу господствующей религии.

В индустриальную эпоху возобладала стратегия ассимиляции, построенная на представлении о чужом как интеллектуально равном человеке, но принадлежащему к отсталому народу. Если научить его нашему языку и местным нравам, то с ним можно конструктивно взаимодействовать. Этому взгляду способствовало развитие антропологии, подтверждавшей биологическое единообразие всех людей.

В постиндустриальную эпоху возобладала стратегия мультикультурализма, построенная на представлении о равенстве всех культур, языков, религий. Каждый человек везде имеет право манифестировать свою культуру в любой форме, и это должно восприниматься как норма.

Ключевые слова: изоляционизм; ассимиляция; мультикультурализм; чужой; чужой в культуре; стратегия отношения

\section{ВВЕАЕНИЕ}

$\mathrm{O}$ тношение к чужим в истории человечества от эпохи к эпохе являлось своеобразным отблеском отношения к своим, выражением экзистенциальной ценности человека вообще. Чужой - это альтернатива своему, и его качества определяются преимущественно в сравнении с качествами своего; оптимально - самого себя.

В доиндустриальную эпоху в условиях страшной антисанитарии жизнь человека практически не ценилась. Смерть была повсюду: 90\% родившихся детей умирали еще в младенчестве, по континентам гуляли страшные эпидемии, женщины часто погибали при родах или становились вдовами в молодые годы и т. П. При таких массовых потерях своих никто и не думал о том, что чужой человек может иметь ценность. 
В индустриальную әпоху санитария жизни начала расти, а смертность падать. Аюди уже привыкли к тому, что жизнь стала более стабильной, и встал вопрос о качестве жизни. Основной стала проблема социальной несправедливости общественного устройства. Отсюда и такая любовь эпохи к революциям, бунтам и пр. Чужой в этих условиях воспринимался уже как сотоварищ по несчастью; нужно только научить его говорить на понятном языке, ассимилировать и включить в борьбу за переустройство мира.

В постиндустриальную эпоху человечество впервые увидело себя целиком (благодаря телевидению и Интернету) и восхитилось красотой своего национальнокультурного многообразия. И тогда оно занялось целенаправленным культивированием этого многообразия, а чужой превратился в особенно ценного носителя разных черт такого многообразия.

В течение истории человечества сменилось несколько оснований, по которым чужого отличали от своего, переменилось общее отношение к нему, от преимущественного отторжения к полному признанию его права на инокультурность. Соответственно, менялись и стратегии политики власти в отношении инокультурных чужих, так же как и стихийное отношение к ним со стороны населения.

Мы усматриваем три принципиальные стратегии в отношении к чужим:

- изоляцию, при которой чужих старались территориально отделить от своих и не допустить их повседневного смешения и контакта;

- ассимиляиию, когда чужим разрешалось смешиваться с местными, но только при условии полного перехода на местный язык и стереотипы бытового поведения;

- мультикультурацию, при которой чужим без ограничений позволяется манифестация собственной культурной специфики при полном бытовом смешении с местными.

Эти стратегии преобладали в разные эпохи. Аля доиндустриальной эпохи была характерна изоляция чужого, для индустриальной эпохи - ассимиляция и для постинустриальной эпохи - мультикультурация. Такая модель в общем схематическом изложении была разработана А. Я. Флиером (Флиер, 2017: Электронный ресурс), а здесь проводится фундаментальное исследование проблемы разных стратегий отношения к чужому в опоре на эту схему.

Прежде всего, не нужно абсолютизировать привязанность этих стратегий к тем или иным эпохам. Такое преобладание имело сугубо статистический характер. В принципе в любую эпоху встречались все три варианта таких стратегий, что определялось суммой внешних обстоятельств или какими-либо ситуативными соображениями. Но статистически стратегия изоляции чужого преобладала в доиндустриальную эпоху, стратегия ассимиляции была характерна для индустриальной эпохи, а стратегия мультикультурализма имеет наибольшее распространение сейчас, в постиндустриальную эпоху.

Причины преобладания той или иной стратегии в ту или иную эпоху очевидны. Аля религиозного сознания доиндустриальной эпохи чужой был создан не по образу и подобию Божьему (нельзя же предположить, что Бог на небе - негр или папуас), а был порождение дьявола, и его следует сторониться. Поэтому в доиндустриальную эпоху доминировала стратегия изоляции чужого. Аля рационального сознания индустриальной эпохи чужой был обычным человеком, но принадлежащим к отсталому народу. Его нужно научить говорить на нашем языке и вести себя так, как мы, и тогда с ним можно иметь дело. Поэтому в индустриальную эпоху господ- 
ствовала стратегия ассимиляции чужого. Аля әгалитаристского сознания постиндустриальной эпохи чужой имеет право быть самим собой, говорить на своем языке и придерживаться норм своей культуры. Если даже его культура и отсталая, она все равно уникальна и бесценна, как и всякая иная культура, и никто не собирается ограничивать чужого в привязанности к своей культуре и ее установкам (Бенхабиб, 2003). Поэтому в постиндустриальную эпоху доминирует стратегия мультикультурализма, т. е. благожелательного отношения к чужому и к любым, даже самым экстравагантным, его культурным проявлениям.

Но рассмотрим это поэтапно.

\section{СТРАТЕГИЯ ИЗОАЯЦИИ В АОИНАУСТРИААЬНУЮ ЭПОХУ}

В доиндустриальную эпоху все чужое воспринималось плохим, подозрительным, сделанным не по нашим правилам, отражающим какие-то иные, не наши критерии качества. Тем более плохими воспринимались чужие культурные проявления, чужие люди, привязанные к такой подозрительной культуре. От них стремились избавиться, изгнать и даже истребить их как существ вредоносных (это было характерным на первобытном этапе истории). Но это не всегда было возможно технически, а в некоторых случаях (в аграрный период истории) политически или экономически считалось неправильным и ограничивалось.

В доиндустриальную эпоху люди были малоподвижны. Мобильный образ жизни вели преимущественно купцы, составлявшие основную массу иноплеменников в городах этой эпохи или жившие в городах постоянно, но занимавшиеся в основном разъездной торговлей. Например, такими были еврейские и мусульманские купцы в городах Западной Европы, итальянцы в Византии, немцы в Аревней Руси. Политическая власть, всегда нуждавшаяся в деньгах, была заинтересована в наличии таких торговцев, обычно готовых помочь власти деньгами, и, как правило, поддерживала их. В противовес этому местное население, не получавшее никакой выгоды от этих купцов, их не любило и было готово к проявлению насилия по отношению к ним (Флиер, 2006). Компромисс был найден в стратегии изолящии подобных чужих в доиндустриальных городах.

Практически это выглядело так. Чужие (инородцы, иноплеменники, но в первую очередь иноверцы) поселялись в городах отдельно; им отводились специальные кварталы, где они могли жить и вести себя в соответствии с нормами своей культуры, исповедовать свою религию и даже строить храмы, самостоятельно поддерживать порядок в соответствии со своими культурными обычаями и пр. (Massey, 2004). Но... им категорически не разрешалось контактировать с местными жителями, демонстрировать им особенности своей культуры и религии. За «переманивание» христианина в свою религию «искуситель» подлежал смертной казни (Штереншис, 2008).

Показательна в этом плане история с так называемой ересью жидовствующих в России конца XV в. Была распространена легенда о том, что многие члены Боярской думы и даже ближайшие родственники царя были охвачены иудейской ересью. Это, конечно же, была политическая провокация, за которой стояла, видимо, вторая жена царя Ивана III, византийская царевна Софья Палеолог (Аурье, 1958; Аихачев, 1987). Но для нас важно то, что такая легенда была актуальной и убедительной для людей того времени, т. е. такая коллизия в средневековой Руси теоретически могла иметь место. 
Таким образом, у общества того времени были все основания опасаться идеологического влияния со стороны чужих, и практика их изоляции в доиндустриальных городах была широко распространена. Иногда дело доходило и до массового изгнания (как, например, изгнание мавров и морисков в Испании 1609-1614 гг., см.: Аиви Баччи, 2010), но чаще дело ограничивалось только изоляцией чужих. В городах стали появляться инородческие (иноверческие) гетто, чайнатауны, немецкая слобода и пр. Контакты чужих с местным населением были строго регламентированы как ситуативно, так и содержательно.

Такая изолированная жизнь большей частью устраивала и самих инородцев, поскольку в какой-то мере оберегала их от агрессии со стороны местных жителей. Стратегия национально-культурной изоляции имела то преимущество, что в той или иной мере препятствовала межнациональным конфликтам, хотя случаи таких конфликтов имели место, и они хорошо известны в истории. Обычно, если защитником инородцев, как правило, выступала политическая власть, заинтересованная в экономическом развитии страны, то Церковь, наоборот, тем или иным образом стимулировала межнациональные конфликты, поскольку была заинтересована в своем безраздельном господстве, а инородцы этому мешали.

Следует сказать, что, если представитель иной расы был все-таки единоверцем воспринимавших его людей (например, эфиоп-христианин), то факт единоверия оказывался более значимым, чем расовое различие. Инородец-единоверец был уже почти своим, хотя определенная специфика в его восприятии сохранялась. Точно так же влияла на восприятие и сословная принадлежность чужого. Негр-царь (скажем, властитель какого-нибудь африканского государства) был уже не вполне негром, а прежде всего царем.

В целом же понимание дилеммы свой/чужой в доиндустриальную эпоху было далеко от какой-то системности, часто опиралось на какие-то случайные и временные решения, но было наполнено страхом за идейную чистоту и неприкосновенность господствующей религии. Нужно напомнить и о том, что в эту эпоху религия была еще и политической идеологией, служение царствующему монарху понималось еще и как религиозный долг человека, так что особая забота о чистоте религии преследовала сразу несколько целей.

\section{СТРАТЕГИЯ АССИМИАЯЦИИ \\ В ИНАУСТРИААЬНУЮ ЭПОХУ}

В индустриальную эпоху отношение к чужому и его культурным отличиям радикально переменилось. Научный прогресс Нового времени и развитие антропологии позволили признать всех людей и даже представителей наиболее отсталых народов интеллектуально более или менее равноспособными. А это значит, что любого человека, хоть из самого отсталого племени, можно воспитать, обучить, развить до цивилизованного уровня (Костина, Флиер, 2009). Нужно только всесторонне его ассимилировать в современном обществе.

Так родилась новая стратегия взаимодействия с чужим - ассимилящионная. Суть ее заключается в том, что социализация чужого в новом обществе должна строиться на его культурно-языковой ассимиляции. Во французском Иностранном легионе не спрашивают, откуда приехал новобранец, и даже не интересуются его настоящим именем. Он должен только владеть французским языком, чтобы понимать команды, и, естественно, владеть какой-либо военной специальностью. В остальном 
его прошлое никого не интересует. Это и есть стратегия ассимиляции в наиболее брутальном ее выражении.

В романе Умберто Эко «Маятник Фуко» есть такой эпизод: один из героев рассказывает остальным исторический анекдот.

Наполеоновский маршал Иоахим Мюрат, объезжая строй своих гусар, увидел чернокожего солдата. Мюрат подъехал к гусару и спросил:

- Вы что, негр?

- Так точно, ваше сиятельство.

- Молодец, - сказал Мюрат. - Так держать (Эко, 2006: 216).

В Средние века солдату не разрешили бы быть негром. Негр - чужой, нехристь. В Новое время - пожалуйста. От чужого не требовалось уже жить в особом квартале. Он мог жить и среди местных, но по языку и стереотипам поведения не должен был от них отличаться, знать законы страны проживания и - желательно - исповедовать ту же религию, что и остальные.

Более того, за закрытой дверью своего дома он мог быть кем угодно - китайцем, зулусом или папуасом и вести себя соответствующим образом. Это его личное дело. Но, перешагнув порог дома, выйдя на улицу, он становился местным и не должен был ничем от них отличаться (Флиер, Полетаева, 2009).

Такое отношение к человеческому потенциалу, конечно, типичная черта Нового времени, когда постулировалась неограниченная обучаемость человека. Вспомним пьесу Б. Шоу «Пигмалион». Это наглядный пример стратегии ассимиляции. Из любого человека можно «вылепить» кого угодно. Нужно только как следует его обучить. Надо сказать, что эта позиция не утратила своей актуальности и сегодня. Отсюда и устойчивость стратегии ассимиляции чужого, которая также актуальна до сих пор.

Разумеется, переход от стратегии изоляции чужого к стратегии его ассимиляции Алился долго и осуществлялся поэтапно. Большинство стран Европы и Америки завершили его в течение XIX в., а в некоторых странах он занял и XX в. Например, Россия совершала его в течение XVIII-XIX вв. (вспомним «арапа Петра Великого» - эфиопа Абрама Ганнибала и его брата, которых царь Петр выписал в Россию именно для борьбы с расовыми предрассудками), а завершила только в начале ХХ в. (Манифест о свободе вероисповедания 1905 г. и революция 1917 г.).

\section{СТРАТЕГИЯ МУАЬТИКУАЬТУРААИЗМА \\ ПОСТИНАУСТРИААЬНОЙ ЭПОХИ}

С наступлением постиндустриальной эпохи приблизительно в последней трети $\mathrm{XX}$ в. произошла и смена стратегии отношения к чужому. Наступила эра мульткультурализма. Но при этом нужно помнить, что постиндустриальной стадии развития пока что достигли лишь полтора-два десятка стран мира, и соответственно, мультикультуральная стратегия проявила себя лишь в Западной Европе, США, Канаде и Австралии. В других странах (даже в Японии) доминирование мультикультурализма в общей культурной жизни и по отношению к чужим не очевидно.

Мультикультуральная стратегия базируется на представлении о том, что все культуры, даже очень отставшие в своем историческом развитии, имеют равную научную и культурную ценность и должны поддерживаться и открыто манифестироваться. Эту позицию разделяет и ЮНЕСКО (Кооманс, 1997). Соответственно, ни о каком подавлении проявлений любых национальных культур или их «вытеснении» 
в процессе ассимиляции в более развитых культурах не может быть и речи. Представители любого народа в любой точке Земли имеют право на открытое манифестирование своей культурной традиции.

Теоретически это выгдядит очень гуманно. Но практически здесь возникает много сложностей. Уже писалось о том, что если представитель развитой цивилизации имеет право и в джунглях Амазонии пользоваться мобильным телефоном, то и амазонский индеец имеет право на улицах Парижа вести себя, как в джунглях: ходить голым, публично испражняться, охотиться если не на прохожих, то уж на кошек и собак и т. п. (Флиер, 2017: Электронный ресурс). Точно так же жители горных аулов Кавказа публично обсуждают и осуждают девушек за то, в каком виде они ходят по улицам Москвы (там же).

Известный американский антрополог С. Бенхабиб посвятила этой проблеме специальную книгу «Притязания культуры» (Бенхабиб, 2003), где описаны множество случаев, как представители полупервобытных народов Индокитая и некоторых иных, переехав в США, продолжают придерживаться своих традиционных семейных обычаев (например, убивают неверных жен), что совершенно не вписывается в американские законы. Однако суды их оправдывают, поскольку это их национальный обычай, т. е. часть их культуры, на которую они имеют право. Это мутикультурализм. Сейла Бенхабиб - сама турецкая еврейка, хорошо знакомая с традиционной культурой как евреев, так турок, - считает, что нельзя в современном обществе давать волю традиционным культурам. С ней солидарен и российский культуролог А. Я. Флиер (Флиер, 2010: Электронный ресурс). Но такая позиция противоречит принципам мультикультуральной стратегии.

Конечно, в мультикультурализме есть и множество положительных сторон. В первую очередь это равное уважительное отношение ко всем народам и культурам. И конечно же, представители традиционных культур в большинстве своем не глупые люди и ведут себя на улицах европейских городов вполне достойно. Но и обратные тому казусы случаются.

Мультикультурализм существует не так много лет, чтобы оформиться в развитую стратегию с четким планом на последовательно решаемые задачи. Сегодня это скорее некоторый бессистемный набор либеральных принципов в решении национальнокультурных проблем. В странах, где еще сильны позиции традиционализма, естественно, мультикультурализм отвергается. Но это скорее общее отторжение западного либерализма в теории, а на практике это, как правило, не выливается в какую-то особую агрессивность по отношению к чужим. В таком латентном виде мультикультурализм как общечеловеческая толерантность имеет широкое распространение в мире.

Важным является и вопрос о том, в какой мере применение той или иной стратегии являлось целенаправленной политикой властей или же стихийным волеизъявлением населения. Представляется, что определенно ответить на этот вопрос невозможно. В каждом конкретном случае могло быть то или другое, а иногда и то, и другое вместе. Существенно то, что в вопросе отношения к чужим позиции властей и населения, как правило, совпадали. Хотя временами эти позиции расходились, и даже бывали конфликты на эту тему.

\section{ЗАКАЮЧЕНИЕ}

Таким образом, мы видим, что все исторические стратегии отношения к чужому строились в основном на теоретическом представлении о нем. Изоляционистская 
стратегия - на представлении о том, что не все люди созданы по образу и подобию Божьему, и потому чужие должны быть истреблены или изолированы. Ассимиляционная стратегия - на представлении о том, что все люди интеллектуально схожи, и все зависит лишь от качества обучения каждого. Мультикультуралистская стратегия - на представлении о том, что все локальные культуры равноценны, все должны быть представлены в своих внешних проявлениях. И хотя каждая из этих стратегий имела определенное историческое тяготение к разным эпохам, на самом деле использование каждой из них имело во многом ситуативный характер и зависело от суммы внешних обстоятельств.

Тем не менее эти стратегии были связаны с общей системой ценностей, преобладавшей в каждую эпоху, и в существенной мере определялись ими. В доиндустриальную эпоху главной ценностью была четкость представлений о делении мира на добро и зло (Флиер, 2015: Электронный ресурс; Флиер, 2019: Электронный ресурс). В индустриальную эпоху в основе иерархии ценностей лежала потребность в большей социальной справедливости (там же). В постиндустриальную эпоху основной ценностью является культурное разнообразие мира, которое должно манифестироваться повсюду (там же).

Отношение к своему и чужому тоже в существенной мере базируется на этом. Оно является своеобразной иллюстрацией всей системы ценностей того или иного народа в ту или иную эпоху, отражая в них свойственные народу представления о добре и зле, о благе и вреде, о жизни и смерти. Чужие - это очень важный элемент общей картины мира в сознании каждого человека и его структуры, осознания человеком своего места в мире.

\section{СПИСОК АИТЕРАТУРЫ}

Бенхабиб, С. (2003) Притязания культуры. Равенство и разнообразие в глобальную әру. М. : \огос. 350 c.

Кооманс, Ф. (1997) ЮНЕСКО и права человека // Введение в вопросы международной защиты прав человека : учеб. пособие / под ред. Р. Хански, М. Сукси. Турку/Або : Университет «Або Академи». 405 с. С. 187-197.

Костина, А. В., Флиер, А. Я. (2009) Три типа культуры - три функциональные стратегии жизнедеятельности // Вестник Челябинской государственной академии культуры и искусств. № 2 (18). C. 23-36.

Аиви Баччи, М. (2010) Аемографическая история Европы. СПб. : Alexandria. 298 с.

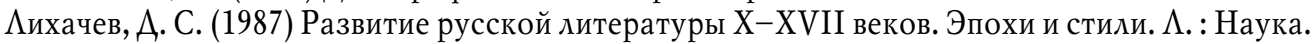
C. 159.

Аурье, Я. С. (1958) Вопрос об идеологических движениях конца XV - начала XVI в. в научной литературе // Труды отдела древнерусской литературы / отв. ред. А. С. Аихачев. М. ; $\Lambda$. : Наука. Т. XV. 523 с. С. 131-152.

Флиер, А. Я. (2006) Культура как репрессия. М. : Аиаграмма. 320 с.

Флиер, А. Я. (2010) Будущее возврату не подлежит (о перспективах развития традиционной культуры) [Электронный ресурс] // Культурологический журнал. № 1. URL: http://www.crjournal.ru/rus/journals/4.html\&j_id=2 (дата обращения: 18.06.2019).

Флиер, А. Я. (2015) Аобро и зло в культурно-историческом понимании [Электронный ресурс] // Информационный гуманитарный портал «Знание. Понимание. Умение». №3. URL: http://www.zpu-journal.ru/e-zpu/2015/3/Flier_Good-Evil/ (дата обращения: 18.06.2019).

Флиер, А. Я. (2017) Варианты культурной политики и стратегии межкультурных взаимодействий [Электронный ресурс] // Культура культуры. №3. URL: http://cult-cult.ru/the-culturalpolicy-options-and-strategies-of-intercultural-interactions/ (дата обращения: 18.06.2019). 
Флиер, А. Я. (2019) Философские пролегомены к Нормативной теории культуры [Электронный ресурс]// Культура культуры. № 1. URL: http://cult-cult.ru/the-philosophical-prolegomenato-a-normative-theory-of-culture/ (дата обращения: 18.06.2019).

Флиер, А. Я., Полетаева, М. А. (2009) Происхождение и развитие культуры. М. : МГУКИ. $272 \mathrm{c}$.

Штереншис, М. (2008) Евреи: история нации. Герцлия : Исрадон. 560 с.

Эко, У. (2006) Маятник Фуко. СПб. : Симпозиум. 736 с.

Massey, D. S. (2004) Segration and Strafication: A Biosocial Perspective. Du Bois Review // Social Science Research on Race. № 1 (1). P. 7-25.

Lата поступления: 02.09.2019 2.

\section{STRATEGIES FOR INTERACTING WITH STRANGERS \\ IN THE WORLD CULTURE}

\section{A. Poletaeva}

MOSCOW STATE LINGUISTIC UNIVERSITY

The article is devoted to the consideration of three main strategies for dealing with strangers that have taken place in history: isolationism, assimilation, and multiculturalism. They were mainly based on the general characteristics of the worldview of a particular era.

In the pre-industrial era, the attitude towards a stranger was mainly based on the strategy of isolationism. Aliens (foreigners, adherents of a different faith) settled separately, in special quarters, and their contacts with the local population were strictly limited. This was based on the notion that strangers were not created in the image and likeness of God, but were born of the devil and threatened the dominant religion.

In the industrial era, an assimilation strategy prevailed, built on the idea of a stranger as an intellectually equal person, but belonging to a backward people. If you teach them your language and local customs, then you can interact with them constructively. This view was facilitated by the development of anthropology, which confirmed the biological uniformity of all people.

In the post-industrial era, a multiculturalism strategy prevailed, based on the idea of the equality of all cultures, languages, and religions. Every person, everywhere has the right to manifest their culture in any form, and this should be perceived as the norm.

Keywords: isolationism; assimilation; multiculturalism; stranger; stranger in culture; strategies of attitude

\section{REFERENCES}

Benkhabib, S. (2003) Pritiazaniia kul'tury. Ravenstvo i raznoobrazie v global' nuiu eru. Moscow, Logos. 350 p. (In Russ.).

Koomans, F. (1997) IuNESKO i prava cheloveka. In: Vvedenie v voprosy mezbdunarodnoi zashchity prav cheloveka : ucheb. posobie / ed. by R. Khanski and M. Suksi. Turku/Abo, Universitet «Abo Akademi». 405 p. Pp. 187-197. (In Russ.).

Kostina, A. V. and Flier, A. Ia. (2009) Tri tipa kul'tury - tri funktsional'nye strategii zhiznedeiatel'nosti. Vestnik Cheliabinskoi gosudarstvennoi akademii kul'tury $i$ iskusstv, no. 2 (18), pp. 23-36. (In Russ.). Russ.).

Livi Bachchi, M. (2010) Demograficheskaia istoriia Evropy. St. Petersburg, Alexandria. 298 p. (In

Likhachev, D. S. (1987) Razvitie russkoi literatury X-XVII vekov. Epokbi i stili. Leningrad, Nauka. 159 p. (In Russ.).

Lur'e, Ia. S. (1958) Vopros ob ideologicheskikh dvizheniiakh kontsa XV - nachala XVI v. v nauchnoi literature. In: Trudy otdela drevnerusskoi literatury/ ed. by D. S. Likhachev. Moscow, Leningrad, Nauka. Vol. XV. 523 p. Pp. 131-152. (In Russ.).

Flier, A. Ia. (2006) Kul' tura kak repressiia. Moscow, Diagramma. 320 p. (In Russ.). 
Flier, A. Ia. (2010) Budushchee vozvratu ne podlezhit (o perspektivakh razvitiia traditsionnoi kul'tury). Kul'turologicheskii zhurnal, no. 1 [online] Available at: http://www.cr-journal.ru/rus/journals/4.html\&j_id=2 (access date: 18.06.2019). (In Russ.).

Flier, A. Ia. (2015) Dobro i zlo v kul'turno-istoricheskom ponimanii. Informatsionnyi gumanitarnyi portal «Znanie. Ponimanie. Umenie», no. 3 [online] Available at: http://www.zpu-journal.ru/e-zpu/2015/3/Flier_Good-Evil/ (access date: 18.06.2019). (In Russ.).

Flier, A. Ia. (2017) Varianty kul'turnoi politiki i strategii mezhkul'turnykh vzaimodeistvii. Kul'tura kul'tury, no. 3 [online] Available at: http://cult-cult.ru/the-cultural-policy-options-andstrategies-of-intercultural-interactions/ (access date: 18.06.2019). (In Russ.).

Flier, A. Ia. (2019) Filosofskie prolegomeny k Normativnoi teorii kul'tury. Kul'tura kul'tury, no. 1 [online] Available at: http://cult-cult.ru/the-philosophical-prolegomena-to-a-normative-theory-of-culture/ (access date: 18.06.2019). (In Russ.).

Flier, A. Ia. and Poletaeva, M. A. (2009) Proiskbozbdenie i razvitie kul'tury. Moscow, MGUKI. 272 p. (In Russ.).

Shterenshis, M. (2008) Evrei: istoriia natsii. Gertsliia, Isradon. 560 p. (In Russ.).

Eko, U. (2006) Maiatnik Fuko. St. Petersburg, Simpozium. 736 p. (In Russ.).

Massey, D. S. (2004) Segration and Strafication: A Biosocial Perspective. Du Bois Review. Social Science Research on Race, no. 1 (1), pp. 7-25.

Submission date: 02.09.2019.

Полетаева Марина Андреевна - кандидат культурологии, доцент кафедры мировой культуры Московского государственного лингвистического университета. Адрес: 119034, Россия, г. Москва, ул. Остоженка, д. 38, стр. 1. Тел.: +7 (499) 246-20-62. Эл. адрес: m.poletaeva@mail.ru

Poletaeva Marina Andreyevna, Candidate of Culturology, Associate Professor, Department of World Culture, Moscow State Linguistic University. Postal address: 38, Bldg. 1, Ostozhenka St., Moscow, Russian Federation, 119034.Tel.: 8 (499) 246-20-62. E-mail: m.poletaeva@mail.ru 